\title{
Hypothetical extraction approach for measuring total economic effects of Croatian ICT sector
}

\author{
Damira Keček ${ }^{1, *}$, Valter Boljunčić ${ }^{2}$, Davor Mikulić ${ }^{3}$ \\ 1 University Center Varaždin, University North \\ 104. brigade 1, 42000 Varaždin, Croatia \\ E-mail: 〈dkecek@unin.hr〉 \\ ${ }^{2}$ Faculty of Informatics, Juraj Dobrila University of Pula \\ Zagrebačka 30, 52100 Pula, Croatia \\ E-mail: 〈vbolj@unipu.hr〉 \\ 3 The Institute of Economics, Zagreb \\ Trg J. F. Kennedyja 7, 10000 Zagreb, Croatia \\ E-mail: 〈dmikulic@eizg.hr〉
}

\begin{abstract}
The aim of this paper is to estimate total effects of the ICT sector to the growth and development of the Croatian economy. Direct, indirect and induced effects for the period 2010-2015 are expressed in terms of output, gross value added and employment. Output, gross value added and employment of ICT sector is estimated by using hypothetical extraction method. Empirical results of conducted analyzes show that the share of Croatian ICT sectors' total effects in terms of output, gross value added and employment during the recession period 2010-2013 was decreasing. In the period of economic recovery 2014-2015, related to the accession process of Republic of Croatia to the European Union, total effects of ICT sector in terms of output, gross value added and employment increased. In 2015 the share of the total effects of the ICT sector in terms of output, gross value added and employment in total Croatian economy amounted to $7.37 \%, 7.74 \%$ and $5.58 \%$ respectively.
\end{abstract}

Keywords: Croatia, hypothetical extraction method, ICT sector, total effects

Received: February 14, 2018; accepted: April 8, 2019; available online: July 4, 2019

DOI: 10.17535 /crorr.2019.0012

\section{Introduction}

In the classical input-output (IO) approach, the final-demand components are treated as exogenous variables. In that context, changes of factors outside the model, induced the changes in domestic production of final goods and services and through inter-sectoral deliveries of intermediate inputs. If contribution of certain economic sector is central question of the research, a different contextualization of the model is required. In that case a mixed type of input-output model is more appropriate. The most common approach that is used to determine the significance of particular sector of interest on whole economy and to calculate total effects of the specific sector, with IO tables applied, is hypothetical extraction method (HEM).

Nowadays, information and communication technology (ICT), takes the key role in productivity growth of modern economies [22] ICT is the key factor at the national and international economic level in innovation, competitiveness and productivity $[6,7,23]$. The significance of

${ }^{*}$ Corresponding author. 
ICT sector is usually explored on the sample of technologically developed economies. In comparison to previous studies, the subject of interest in this study is the role of ICT sector in Croatia, as an economy which lags behind in the application of technologically advanced production processes. The research question is whether the ICT sector is significant in deindustrialized economy specialized in activities belonging low and middle technology.

The role of the ICT sector in domestic literature is insufficiently explored. Therefore, the goal of this paper is to empirically quantify direct, indirect and induced effects of ICT sector by using hypothetical extraction method. Results will contribute to a widespread understanding of the impact and importance of the ICT sector for Croatian economy.

The paper consists of several sections. After the introduction, review of the relevant literature in which HEM is applied in the analysis of the importance of different sectors is presented in Section 2. Methodology is presented in Section 3 and data sources in Section 4. Section 5 presents estimation of total effects of ICT sector for Croatian economy. Last section (Section 6) summarizes conclusion and provides basis for future research.

\section{Literature review}

The powerful analytical tool of quantitative macroeconomic analysis that estimates total effects of a certain sector of interest is the input-output (IO) analysis [19, 20, 23]. Total effects quantified by IO analysis are defined as a sum of direct, indirect and induced effects. The statistical-information base with analysis are IO tables. In its basic form, IO model represents a system of linear equations that in detail show the relationship between different activities in the national economy. Each equation shows the production distribution of a certain activity to intermediate consumption and final use of the total economy. The scope of the classical IO approach is multipliers type I and type II calculation, i.e. the calculation of indicators that are interpreted as effects of the change in final demand on overall economic activity.

The review of the relevant literature indicates that HEM is applied in the effects and importance analysis of many sectors of national economies. The importance of the Iranian ICT sector was analyzed in [2] by using HEM. Both on the demand and on the supply side ICT sector was positioned on fourth place with regard to the sector's importance. Economic effects of real estate sector of OECD member countries were analyzed [26]. Results of the provided analysis indicated increasing trend of total effects and backward and forward linkages and real estate sector growth. On the other hand, in [28] a new model for backward and forward linkages calculation, based on HEM, was developed. Authors concluded that in research [26] linkages of real estate sector were underestimated. Similar results and conclusions were made in the paper [29]. Increasing impact of real estate-construction sector for 30 provinces in China was showed in [24]. According to the obtained results, weighted average impact of the analyzed sector in 2002 accounted to $21 \%$ of total output and $14 \%$ of all jobs, while in 2007 , accounted to $23 \%$ of total output and $22 \%$ of all work places. The importance of construction sector of OECD countries was analyzed in [27]. Total, backward and forward linkages declined which lead to the conclusion that importance of construction sector in observed economies is reduced. In [14], the relationship between the energy and non-energy sectors and radiation levels in Spain for the year 2004 was investigated. Authors concluded that electricity sector had the highest average impact and the lowest variability of all energy sectors. The importance of services in New York State was analyzed in [17]. Results of analysis indicate that importance of services sector in New York State was crucial.

HEM is not only used for analyzing the importance of specific sector of interest or effects calculation. HEM is also applied for key sectors identification. A combination of traditional IO methods and HEM is applied in [15] to identify key sectors for electricity generation and distribution. It was found that electricity sector affects other energy sectors almost the same as some manufacturing sectors. In [30, 31] following key sectors crucial for more efficient water use 
and reduction of $\mathrm{CO} 2$ emissions in Australia were identified: beef cattle and electricity, dairy cattle and water supply, sewerage and drainage services. Dependence of agriculture sectors on urban sectors in Beijing was evaluated in [35]. Identified key urban sectors that were related with development of agriculture were: food processing and food services, construction, pharmaceutical, tourism, hotels, information and technology services, business services, finance and health care sector. By using HEM, following key sectors were identified for China: agriculture, textiles, chemicals, building materials, primary metals, machinery, commerce and other services $[1]$.

Despite the numerous analytical possibilities that can be performed by IO model, the number of relevant and recent domestic and international research quantifying and analyzing economic effects of ICT sector is relatively modest. Multipliers of ICT sectors for Croatian economy were estimated in [18]. Between multipliers of Croatian ICT and non-ICT sectors there was no significant difference, while significant difference was noticed in observed indicators of new and old European Union (EU) members. ICT sector had greater impact on the economic growth and development of the long-standing European Union member states. Significance of Italian ICT sector was quantified by using output multipliers [8]. In [25] IO methodology was applied to quantify multipliers effects of ICT sector for some European countries. Obtained results indicate reduced production of the ICT sector. In [16] the importance of ICT sector was analyzed by using IO method for four Southeast Asian countries. According to the results of intersectoral linkages, ICT sector is recognized as a key sector for export expansion in Singapore $[33]$.

\section{Research methodology}

\subsection{Methods}

According to [4] HEM is based on the hypothetical extraction of one or more productive sectors and evaluation of the impact of extracted sector to other sectors in the economy. By using HEM, total effects of extracted sector to other sectors or to the whole economy can be quantified [9]. In general, total effects are calculated in terms of output, gross value added (GVA) and employment. Direct effects of particular sector are determined by direct deliveries of goods and services of that sector to final consumers. Indirect effect of an observed sector relates to output, GVA and employment in value added chain of that sector. Induced effects are effects that arise with personal consumption growth.

The original idea of HEM is quantification of hypothetical reduction in output created in the overall economy if a certain sector of interest is extracted from the economic system [21]. Let matrix A be square $n \times n$ matrix

$$
\mathbf{A}=\left[\begin{array}{cccc}
a_{11} & a_{12} & \ldots & a_{1 n} \\
a_{21} & a_{22} & \ldots & a_{2 n} \\
\vdots & \vdots & \ddots & \vdots \\
a_{n 1} & a_{n 2} & \ldots & a_{n n}
\end{array}\right]
$$

where elements $a_{i j}$ are called technical coefficients, i.e. $a_{i j}=\frac{X_{i j}}{X_{j}}$.

The certain sector, for example sector $j$, is extracted from the economic system by deleting the row and the column belonging to sector $j$ in the matrix $\mathbf{A}$. Let $\mathbf{A}_{E}$ be $(n-1) \times(n-1)$ matrix obtained by deleting $j$-th row and $j$-th column in $\mathbf{A}$. Furthermore, let $\mathbf{X}$ be a column vector of outputs and $\mathbf{Y}$ a column vector of final demands: 


$$
\mathbf{X}=\left[\begin{array}{c}
x_{1} \\
x_{2} \\
\vdots \\
x_{n}
\end{array}\right] \quad \mathbf{Y}=\left[\begin{array}{c}
y_{1} \\
y_{2} \\
\vdots \\
y_{n}
\end{array}\right]
$$

By extraction sector $j$, the element $y_{j}$ in the column vector $\mathbf{Y}$ is also deleted. Let $\mathbf{Y}_{E}$ be be the column vector obtained by deleting element $y_{j}$ in the $\mathbf{Y}$.

In the IO model where $\mathrm{n}$ sectors are observed, total production of the economy can be calculated according to matrix equation:

$$
\mathbf{X}=(\mathbf{I}-\mathbf{A})^{-1} \mathbf{Y}
$$

where $\mathbf{I}$ is $n \times n$ identity matrix. Matrix $\mathbf{L}=(\mathbf{I}-\mathbf{A})^{-\mathbf{1}}$ is known as Leontief inverse matrix. More detailed description of IO model can be found in [19, 20, 32]. For matrix $\mathbf{A}_{E}$ and column $\bar{Y}$, total production of the economy where $n-1$ sectors are observed, equals to $\bar{X}=\left(\mathbf{I}-\mathbf{A}_{\mathbf{E}}\right)^{-\mathbf{1}} \mathbf{Y}_{\mathbf{E}}$ where $\mathbf{I}$ is $(n-1) \times(n-1)$ identity matrix. The difference:

$$
i^{\tau} \mathbf{X}-i^{\tau} \bar{X}
$$

where $i^{\tau}$ is row vector of appropriate dimension units, i.e. the difference of total production before and after extracting of sector $j$. Thus, $\bar{X}$ measures the economic loss generated by extraction of the sector $j$. The difference in eq.(2) measures the importance of the sector $j$ to the whole economy $[10,20]$. In $[20,21]$ authors represented a method of the $j$-th sector extracting not by deleting the $j$-th row and $j$-th column in matrix $\mathbf{A}$, but by replacing the $j$-th row or $j$-th column in matrix $\mathbf{A}$ with zeroes. A detailed overview of all six possible ways of extracting the certain sector or more of them is provided in [21]. This approach of extracting sector by replacing a certain row with zeroes is applied in this paper and explained in more detail below.

Suppose that $n-k$ sectors are being extracted. Then, in the matrix $\mathbf{A}$ all last $n-k$ rows are replaced with zeroes. It needs to be emphasized that the order of the sectors does not affect the total effects calculation of the observed sectors. In this paper the order as presented in the referenced papers has been used. By replacing last $n-k$ rows with zeroes, matrix $\mathbf{A}$ now has the following form:

$$
\tilde{\mathbf{A}}=\left[\begin{array}{ll}
\mathbf{A}_{\mathbf{k}, \mathbf{k}} & \mathbf{A}_{\mathbf{k}, \mathbf{n}-\mathbf{k}} \\
\mathbf{O}_{\mathbf{n}-\mathbf{k}, \mathbf{k}} & \mathbf{O}_{\mathbf{n}-\mathbf{k}, \mathbf{n}-\mathbf{k}}
\end{array}\right]
$$

where $\mathbf{A}_{\mathbf{k}, \mathbf{k}}$ is $(k \times k)$ sub-matrix, $\mathbf{A}_{\mathbf{k}, \mathbf{n}-\mathbf{k}}$ is $(k \times n-k)$ sub-matrix of matrix $\mathbf{A}$ and $\mathbf{O}$ is null matrix of appropriate dimension. Leontief inverse matrix now has the form:

$$
\tilde{\mathbf{L}}=(\mathbf{I}-\tilde{\mathbf{A}})^{-1}=\left[\begin{array}{lc}
\left(\mathbf{I}-\mathbf{A}_{\mathbf{k}, \mathbf{k}}\right)^{-1} & \left(\mathbf{I}-\mathbf{A}_{\mathbf{k}, \mathbf{k}}\right)^{-1} \mathbf{A}_{\mathbf{k}, \mathbf{n}-\mathbf{k}} \\
\mathbf{O}_{\mathbf{n}-\mathbf{k}, \mathbf{k}} & \mathbf{I}_{\mathbf{n}-\mathbf{k}, \mathbf{n}-\mathbf{k}}
\end{array}\right]
$$

Furthermore, let $\mathbf{X}_{\mathbf{K}}$ be a column vector of outputs of the first $k$ sectors and $\mathbf{X}_{\mathbf{N}-\mathbf{K}}$ a column vector of outputs of remaining $n-k$ sectors:

$$
\mathbf{X}_{\mathbf{K}}=\left[\begin{array}{c}
x_{1} \\
x_{2} \\
\vdots \\
x_{k}
\end{array}\right] \quad \mathbf{X}_{\mathbf{N}-\mathbf{K}}=\left[\begin{array}{c}
x_{k+1} \\
x_{k+2} \\
\vdots \\
x_{n}
\end{array}\right]
$$

and $\mathbf{Y}_{\mathbf{K}}$ the column vector of final demand of the first $k$ sectors and $\mathbf{Y}_{\mathbf{N}-\mathbf{K}}$ a column vector of final demand of remaining $n-k$ sectors: 


$$
\mathbf{Y}_{\mathbf{K}}=\left[\begin{array}{c}
y_{1} \\
y_{2} \\
\vdots \\
y_{k}
\end{array}\right] \quad \mathbf{Y}_{\mathbf{N}-\mathbf{K}}=\left[\begin{array}{c}
y_{k+1} \\
y_{k+2} \\
\vdots \\
y_{n}
\end{array}\right]
$$

Then, equation:

$$
\tilde{\mathbf{X}}=\left[\begin{array}{l}
\mathbf{X}_{\mathbf{K}} \\
\mathbf{X}_{\mathbf{N}-\mathbf{K}}
\end{array}\right]=\tilde{\mathbf{L}}\left[\begin{array}{l}
\mathbf{Y}_{\mathbf{K}} \\
\mathbf{Y}_{\mathbf{N}-\mathbf{K}}
\end{array}\right]=\left[\begin{array}{ll}
\left(\mathbf{I}-\mathbf{A}_{\mathbf{k}, \mathbf{k}}\right)^{-1} & \left(\mathbf{I}-\mathbf{A}_{\mathbf{k}, \mathbf{k}}\right)^{-1} \mathbf{A}_{\mathbf{k}, \mathbf{n}-\mathbf{k}} \\
\mathbf{O}_{\mathbf{n}-\mathbf{k}, \mathbf{k}} & \mathbf{I}_{\mathbf{n}-\mathbf{k}, \mathbf{n}-\mathbf{k}}
\end{array}\right]\left[\begin{array}{l}
\mathbf{Y}_{\mathbf{K}} \\
\mathbf{Y}_{\mathbf{N}-\mathbf{K}}
\end{array}\right]
$$

represents the total output of $n-k$ sectors. In this context, total effects in terms of output equals to sum of direct and indirect effects. To calculate the total effects of sectors of interest in terms of GVA, following formula is used:

$$
\tilde{\mathbf{V}}=\mathbf{V} \tilde{\mathbf{L}}\left[\begin{array}{l}
\mathbf{Y}_{\mathbf{K}} \\
\mathbf{Y}_{\mathbf{N}-\mathbf{K}}
\end{array}\right]
$$

where $\mathbf{V}$ is diagonal matrix, containing value added coefficients on the main diagonal, i.e. $\tilde{v}_{i}=\frac{v_{i}}{X_{i}}, \quad i=1,2, \ldots, n$.

Direct and indirect effects of sectors of interest in terms of employment can be calculated according to formula:

$$
\tilde{\mathbf{E}}=\mathbf{E} \tilde{\mathbf{L}}\left[\begin{array}{l}
\mathbf{Y}_{\mathbf{K}} \\
\mathbf{Y}_{\mathbf{N}-\mathbf{K}}
\end{array}\right]
$$

where $\mathbf{E}$ is diagonal matrix with employment coefficients on the main diagonal, i.e. $\tilde{e}_{i}=$ $\frac{e_{i}}{X_{i}}, \quad i=1,2, \ldots, n$. Besides direct and indirect effects, to calculate also induced effects, the procedure described above remains the same, only that instead of initial matrix $\mathbf{A}$, expanded matrix $\overline{\mathbf{A}}$ with one more row representing compensation of employees coefficients and one more column representing household consumption coefficients is applied.

\subsection{Data}

The main data source in this research is Croatian IO table for 2010 [5]. According to the European standards for publishing the IO tables, Croatian IO table for the year 2010 is made on the basis of 64 productive sectors which are linked to the NCA 2007 classification sections. Products classification used in the IO table for 2010 preparation is the CPA 2008. The IO table for 2010 is made with separated domestic production and import. The IO table for the year 2010 is expressed in basic prices including the purchaser's price transformation. Nowadays, it is last published IO table for the Croatian economy. According to the definition for the identification of the ICT economic activities [34], ICT sector includes ICT manufacturing industry, i.e. sector code CPA-C26 - Computer, electronic and optical products; ICT trade industry, i.e. sector code CPA-G46 - Wholesale trade services, except for motor vehicles and motorcycles and ICT services industries, i.e. sector code CPA-J58 - Publishing services, sector code CPA-J61 - Telecommunications services, sector code CPA-J62-J63 - Computer programming, consultancy and related services, information services and sector code CPA-S95 - Repair services of computers and personal and household goods. Sector codes CPA-G46, CPA-J58 and CPA-S95 besides ICT activities include also activities which do not have features of ICT. Therefore, the application of the IO table for the total effects calculation purposes of the ICT sector requires the transformation of original data. Transformation is based on the integration of IO tables and data from [13]. 
Economic aggregates used in this research are output, GVA and employment. The mentioned aggregates definitions are taken from the ESA 2010. Output is defined as market value of all produced goods and services. The gross value added equals to the difference between gross value of production and intermediate consumption. Intermediate consumption shows the value of all intermediate goods and services used in the production process. Employment equals to number of jobs in an economy. The required data for the calculation of total effects in terms of GVA and employment of ICT sector are downloaded from [11] and [12].

\section{Research results}

This section provides results of the direct, indirect and induced effects calculation of the ICT sector in terms of output, GVA and employment. Also, the share of the ICT sector in total Croatian output, GVA and employment for the analyzed period 2010-2015 is presented.

Table 1 represents total effects of ICT sector on the total Croatian economy in terms of output, GVA and employment in the period 2010-2015, with the composition on direct, indirect and induced effects. Direct effects in terms of output and GVA of ICT sector on the Croatian economy are relatively higher than the sum of indirect and induced effects. In comparison to 2013, in 2014 and 2015 direct, indirect and induced effects in terms of output and GVA are growing and for the future period indicators' stabilization is expected. Unlike the specificity of direct effects of ICT sector in terms of output and GVA, sum of indirect and induced employment effects of ICT sector is significantly higher. It is obvious that the number of employees significantly increased in the period after 2013. In 2015, with the total output of approximately 42 billion kuna, ICT sector in the Croatian economy generated approximately 22 billion kuna of GVA and almost 89 thousand of work places.

\begin{tabular}{|l|rrrrrr|}
\hline OUTPUT & 2010 & 2011 & 2012 & 2013 & 2014 & 2015 \\
\hline Direct effects & 22.26 & 22.43 & 22.57 & 21.91 & 22.15 & 23.67 \\
Indirect effects & 6.71 & 6.75 & 6.77 & 6.53 & 6.74 & 7.21 \\
Induced effects & 9.95 & 10.02 & 10.18 & 9.97 & 10.23 & 11.15 \\
Total effects & 38.92 & 39.20 & 39.52 & 38.41 & 39.12 & 42.03 \\
\hline GVA & & & & & & \\
Direct effects & 13.04 & 12.49 & 12.29 & 11.91 & 11.98 & 12.59 \\
Indirect effects & 3.19 & 3.22 & 3.20 & 3.11 & 3.23 & 3.48 \\
Induced effects & 5.20 & 5.14 & 5.20 & 5.13 & 5.27 & 5.76 \\
Total effects & 21.43 & 20.06 & 20.69 & 20.15 & 20.48 & 21.83 \\
\hline EMPLOYMENT & & & & & & \\
Direct effects & 33672 & 33913 & 31252 & 33083 & 36838 & 39623 \\
Indirect effects & 17613 & 16307 & 16084 & 15023 & 16586 & 18752 \\
Induced effects & 31852 & 29653 & 28921 & 27258 & 28253 & 30553 \\
Total effects & 83137 & 79872 & 76257 & 75364 & 81677 & 88928 \\
\hline
\end{tabular}

Table 1: Output, GVA and employment induced by ICT sector (output and GVA in million kuna; employment in number of employees) 


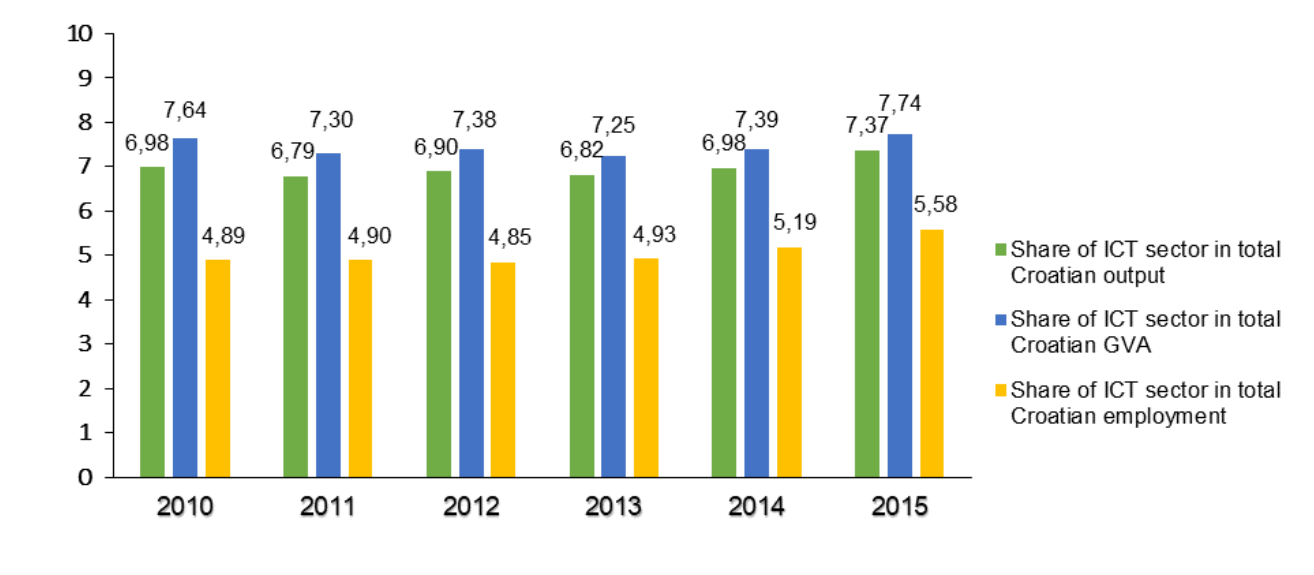

Figure 1: Share of ICT sector in total Croatian output, GVA and employment

In Figure 1 share of output, GVA and employment of ICT sector in total Croatian output, GVA and employment in the period 2010-2015 is shown. During the observed period, oscillations of share of output, GVA and employment of ICT sector in total output, GVA and employment in Republic of Croatia were recorded. Oscillations of those values are the result of different processes and changes in certain sectors. The share of ICT sector, measured in output, gross value added and employment, decreased in period 2010-2013 as a result of a decrease of real income of households. Revival of domestic economy, coupled by growth in employment and household income induced rise in the share of ICT sector.

Therefore, it can be concluded that the elasticity of demand for ICT goods and services to income is above unity. In 2015, the share of ICT sector in total Croatian output, GVA and employment recorded largest values and amounted to $7.37 \%, 7.74 \%$ and $5.58 \%$ respectively. It is interesting to note that the share of ICT sector in terms of GVA is significantly higher than share in terms of employment. It is result of higher productivity of ICT activities in comparison to the average national productivity. Having in mind favorable economic conditions and stable economic growth in recent period, it could be expected that current share of ICT sector is even higher, but unfortunately official data on direct effects are still not available.

\section{Conclusion}

ICT sector is recognized as a significant sector that has the role of leader sectors in economic growth and development of modern economies. This research analysis the impact of ICT sector on Croatian economy by using HEM. Direct, indirect and induced effects for the period 20102015 are calculated. The long-lasting recession, that lasted until 2014, marked observed period with a low demand for ICT goods and services. By accession of the Republic of Croatia into the EU, the quality and scope of ICT goods and services was improved due to different adaptations to European regulations in the ICT sector.

In comparison to the previous studies which primarily includes the more developed economy $[8,25,33]$ it can be concluded that the role of ICT is less pronounced in the Croatia. Croatia lags behind primarily in the manufacturing industry producing ICT goods. While application of modern technological processes generally present main factor of export competitiveness in more developed economies, in Croatian case, the contribution of service sector including 
telecommunication and computer programing is more important. However, results points to the conclusion that ICT sector is to be treated as one of the key economic sectors, even in an economy lagging behind regarding application of the modern technologies. If compared to the official national accounts data, the total contribution of ICT sector in Croatia is above some traditionally important economic sectors such as agriculture or transport.

Practical implications of this research can be summarized in the analytical basis for a whole range of complementary research, such as research concerning economic growth and productivity. The empirical results on trends of ICT sector could be valuable for academic and general public, because they provide overall assessment of total effects of ICT sector in Croatia based on the sound methodological framework. Based on the analytical basis, arising out of the research results more efficient economic policy measures for stimulating ICT sector could be formulated.

The main limitation of this research is the inability to monitor changes in technical coefficients due to the lack of a new IO table for the year 2015. The assumption of the constant technical coefficients is acceptable in a short period and the results obtained are more relevant when the year in which the analysis was conducted is closer to the year in which the IO table was compiled.

For future research it is expected to evaluate total effects for more recent period. New calculations will be based on the IO table for the year 2015, which is expected to be published presently. Except the possibility of comparing the impact of the ICT sector on the basis of two IO tables for different reference periods, the calculation and analysis of the effects of ICT sector for other EU economies would be of great importance. Apart from the national level, such an analysis would allow consideration of the importance of the ICT sector internationally.

\section{References}

[1] Andreosso-O'Callaghan, B. and Yue, G. (2004). Intersectoral Linkages and Key Sectors in China, 1987-1997. Asian Economic Journal, 18(2), 165-183. doi: 10.1111/j.1467-8381.2004.00188.x

[2] Bazzazan, F. (2009). The Economic Importance of ICT in Iran-Input-Output Approach. Proceedings of the International Conference on Information and Financial Engineering, 1-7. doi: 10.1109/icife.2009.11

[3] Burrows, L. R. and Botha, A. P. (2013). Explaining the changing input-output multipliers in South African: 1980-2010. Proceedings of the Biennial Conference of the Economic Society of South Africa, 1-33.

[4] Cella, G. (2009). The Input-Output Measurement of Interindustry Linkages. Oxford Bulletin of Economics and Statistics, 46(1), 73-84. doi: 10.1111/j.1468-0084.1984.mp46001005.x

[5] Croatian Bureau of Statistics. (2018). Input-output table for 2010 supply and use tables for 2010. https://www.dzs.hr [Accessed 18/12/2018].

[6] Dedrick, J., Kraemer, K. L. and Shih, E. (2013). Information Technology and Productivity in Developed and Developing Countries. Journal of Management Information Systems, 30(1), 97122. doi: $10.2753 / \mathrm{mis} 0742-1222300103$

[7] Dewan, S. and Kraemer, K. L. (2000). Information Technology and Productivity: Evidence from Country-Level Data. Management Science, 46(4), 548-562. doi: 10.1287/mnsc.46.4.548.12057

[8] Di Carlo, C. and Santarelli, E. (2010). Contribution of ICT to economic growth in Italy: Input Output analysis. Ministry of Economic Development, Department of Communications.

[9] Dietzenbacher, E. and van der Linden, J. A. (1997). Sectoral and spatial linkages in the EC production structure. Journal of Regional Science, 37(2), 235-257. doi: 10.1111/0022-4146.00053

[10] Dietzenbacher, E., van Burken, B. and Kondo, Y. (2019). Hypothetical extractions from a global perspective. Economic Systems Research, 1-15. doi: 10.1080/09535314.2018.1564135

[11] Eurostat (2018a). Eurostat National accounts aggregates by industry. http://ec.europa.eu/ eurostat/data/database [Accessed 20/12/2018].

[12] Eurostat (2018b). Eurostat National accounts employment data by industry. http://ec.europa. eu/eurostat/data/database [Accessed 20/12/2018]. 
[13] Eurostat Structural Business Statistics (2018). Structural Business Statistics Data. http://ec. europa.eu/eurostat/web/structural-business-statistics [Accessed 17/12/2018].

[14] Guerra, A. I. and Sancho, F. (2010). Measuring Energy Linkages with the Hypothetical Extraction Method: An application to Spain. Energy Economics, 32(4), 831-837. doi: 10.1016/j.eneco.2009.10.017

[15] Guerra, A. I. (2014). A proposal to combine classical and hypothetical extraction input-output methods to identify key sectors for the production and distribution of electricity. Energy Efficiency, 7(6), 1053-1066. doi: 10.1007/s12053-014-9272-8

[16] Irawan, T. (2014). ICT and economic development: Comparing ASEAN member states. International Economics and Economic Policy, 11(1-2), 97-114. doi: 10.1007/s10368-013-0248-5

[17] Kay, D. L., Pratt, J. E. and Warner, M. E. (2007). Role of Services in Regional Economy Growth. Growth and Change, 38(3), 419-442. doi: 10.1111/j.1468-2257.2007.00377.x

[18] Keček, D., Žajdela Hrustek, N. and Dušak, V. (2016). Analysis of multiplier effects of ICT sectors - a Croatian case. Croatian Operational Research Review, 7(1), 129-145. doi: /10.17535/crorr.2016.0009

[19] Mikulić, D. (2018). Osnove input-output analize s primjenom na hrvatsko gospodarstvo. Zagreb: Ekonomski institut.

[20] Miller, R. E. and Blair, P. D. (2009). Foundations of Input-Output Analysis, 10-68. In InputOutput Analysis: Foundations and Extensions. New York: Cambridge University Press. doi: $10.1017 /$ cbo9780511626982.003

[21] Miller, R. E. and Lahr, M. L. (2001). A taxonomy of extractions, 407-441. In Regional Science Perspectives in Economics: A Festschrift in Memory of Benjamin H. Stevens. Amsterdam: Elsevier Science. https://papers.ssrn.com/sol3/papers.cfm?abstract_id=658161

[22] Pohjola, M. (2002). The New Economy in Growth and Development. Oxford Review of Economic Policy, 18(3), 380-396. doi: 10.1093/oxrep/18.3.380

[23] Popova, I., Popov, O. and Dalin, R. (2005). ICT knowledge 4 ICT diffusion. Information and Communication Technologies and the Knowledge Economy, 2, 792-799.

[24] Ren, H., Folmer, H. and Van der Vlist, A. J. (2014). What role does the real estate-construction sector play in China's regional economy? The Annals of Regional Science, 52(3), 839-857. doi: 10.1007/s00168-014-0613-5

[25] Rohman, I. K. (2013). The globalization and stagnation of the ICT sectors in European countries: An input-output analysis. Telecommunications Policy, 37(4-5), 387-399. doi: 10.1016/j.telpol.2012.05.001

[26] Song, Y., Liu, C. and Langston, C. (2005). A linkage measures framework for the real estate sector. International Journal of Strategic Property Management, 9(3), 121-143. doi: 10.3846/1648715x.2005.9637533

[27] Song, Y., Liu, C. and Langston, C. (2006a). Linkage measures of the construction sector using the hypothetical extraction method. Construction Management and Economics, 24(6), 579-589. doi: 10.1080/01446190500435358

[28] Song, Y., Liu C. and Langston, C. (2006b). Linkage measures of the real estate sector considering the effect of capital. International Journal of Strategic Property Management, 10(3), 131-143. doi: 10.3846/1648715x.2006.9637549

[29] Song, Y. and Liu, C. (2007). An Input-Output Approach for Measuring Real Estate Sector Linkages. Journal of Property Research, 24(1), 71-91. doi: 10.1080/09599910701297697

[30] Temurshoev, U. (2009). Hypothetical extraction and fields of influence approaches: integration and policy implications. EERC Working Paper Series, 09/06. https://ideas.repec.org/p/eer/ wpalle/09-06e.html

[31] Temurshoev, U. (2010). Identifying optimal sector groupings with the hypothetical extraction method. Journal of regional science, 50(4), 872-890. doi: 10.1111/j.1467-9787.2010.00678.x

[32] Ten Raa, T. (2005). Environmental input-output economics, 139-150. In The Economics of InputOutput Analysis. Cambridge: Cambridge Univeristy Press. doi: 10.1017/cbo9780511610783.013

[33] Toh, M. H. and Thangavelu, S. M. (2013). An input-output study of the Singapore information sector. Economic Systems Research, 25(2), 233-244. doi: 10.1080/09535314.2012.740616

[34] United Nations. (2008). International standard industrial classification of all economic activities (ISIC). Statistical paper Series, Department of Economic and Social Affairs, M4/Rev4. https: 
//unstats.un.org/unsd/publication/seriesM/seriesm_4rev4e.pdf

[35] Yang, Z., Cai, J., Dunford, M. and Webster, D. (2014). Rethinking of the Relationship between Agriculture and the "Urban" Economy in Beijing: An Input-Output Approach. Technological and economic development of economy, 20(4), 624-647. doi: 10.3846/20294913.2014.871661 